\title{
PROJETOS PEDAGÓGICOS NA EDUCAÇÃO INFANTIL: RELATOS DE VIVÊNCIAS
}

\author{
Flávia Pimenta de Souza Carcanholo \\ Eseba / UFU \\ flaviapimentasouza@yahoo.com.br
}

Resumo: Este trabalho tem como objetivo compartilhar experiências sobre projetos
desenvolvidos na Educação Infantil como forma de propiciar situações de ensino e
aprendizagem. Os projetos envolvem a participação ativa dos alunos como protagonistas deste processo. Por meio do olhar atento do professor aos interesses da turma um tema pode ser definido como eixo para uma pesquisa. Neste relato, são abordados diversos temas trabalhados, um em cada ano letivo. É possível verificar as variadas linguagens sendo exploradas no contexto dos projetos de pesquisas com temáticas escolhidas no próprio universo infantil. Em todos os projetos trabalhados houve a preocupação com o levantamento de ideias nas quais as crianças eram instigadas a todo o momento para a criação de hipóteses, inquietações, busca pela pesquisa e descoberta de novas informações que desencadeavam para a problemática dos projetos. O envolvimento da turma era visível e corroborava para uma aprendizagem e uma vivência prazerosa no cotidiano escolar. O planejamento era feito concomitantemente com as ações e as atividades iam sendo construídas "durante o caminho". Inicialmente era levantado com a turma o que já sabiam sobre o tema, o que gostariam de saber mais e de que forma conseguiriam descobrir. Por meio dos projetos, foi possível abranger as habilidades e competências das áreas curriculares imersas no Programa Curricular da Educação Infantil, como Linguagem Oral e Escrita, Matemática, Natureza e Sociedade, Desenvolvimento Afetivo e Emocional, Movimento e Arte. Os temas trabalhados, um em cada ano de ensino foram: golfinho, meteoro, natureza, cigarra, macaco, cachorro, macarrão, dinossauro e foguete. Ao longo do trabalho eram elaborados registros por meio de fotos, desenhos, imagens, livretos, construções de sucatas que compõem os elementos trabalhados no projeto e que culminam em uma exposição e apresentação à comunidade escolar do trabalho desenvolvido pela turma. A avaliação quanto à participação e aprendizagem dos alunos acontece de maneira processual, durante todo o desenvolvimento do projeto. Sendo assim, os projetos propiciam uma maneira de olhar para a criança como protagonista de seu processo de aprendizagem, sendo ela curiosa, criativa, alguém que se interessa e é estimulada a procurar soluções e compreender o mundo a sua volta. , macarrão, dinossauro e foguete. Ao longo do trabalho eram elaborados registros por meio de fotos, desenhos, imagens, livretos, construções de sucatas que compõem os elementos trabalhados no projeto e que culminam em uma exposição e apresentação à comunidade escolar do trabalho desenvolvido pela turma. A avaliação quanto à participação e aprendizagem dos alunos acontece de maneira processual, durante todo o desenvolvimento do projeto. Sendo assim, os projetos 
propiciam uma maneira de olhar para a criança como protagonista de seu processo de aprendizagem, sendo ela curiosa, criativa, alguém que se interessa e é estimulada a procurar soluções e compreender o mundo a sua volta.

\section{Introdução}

A Educação Infantil é um espaço e um momento da vida das crianças que possibilita a ampliação do seu universo familiar, almejando incitar a curiosidade infantil, alimentá-la com vivências instigantes de modo que a aprendizagem e o seu desenvolvimento aconteçam de maneira natural e significativa. O professor de Educação Infantil precisa ter um olhar atento e uma escuta ativa às diversas e provocantes possibilidades de estudos e trabalhos a partir das conversas, dos interesses e das inquietações das crianças a cerca do mundo em que estão inseridas. Como bem coloca Osteto (2000, p. 194) "A escuta é disponibilidade ao outro e a tudo que ele tem a dizer. E mais: a escuta torna-se, hoje, o verbo mais importante para se pensar e direcionar a prática educativa".

A proposta curricular da escola é a base do planejamento que pode ser desenvolvido em sala de aula, sendo que o professor pode fazer escolhas de como desenvolver o seu trabalho, isto é, podendo optar por metodologia participativa, integradora, priorizando o que considera importante para o processo de aprendizagem dos alunos. Estas escolhas são fundamentais para desencadear um bom trabalho, com propriedade e qualidade.

Para tanto, é preciso que o professor enquanto mediador do trabalho a ser desenvolvido e das interações que ocorrem no espaço escolar esteja sempre atento a "importância do olhar detalhado para essas interações e da escuta atenta por parte do professor, sendo o tradutor, interprete e organizador das falas das crianças" (OLIVEIRA; FERREIRA, 2016, p. 57). Desta forma, o currículo para a educação infantil, ao mesmo tempo de contempla as diversas linguagens curriculares, como movimento, arte, oral e escrita, matemática, natureza e sociedade, desenvolvimento emocional, pode ser estruturado e concretizado com uma maneira de trabalhar de forma flexível, a partir das falas das crianças, de suas inquietações e curiosidades.

Um currículo escolar que reflita o meio social e cultural das crianças, em que as áreas de conhecimento sejam transversalizadas e considerem a realidade e as experiências cotidianas do aluno, para chegar à sistematização do saber. Nessa perspectiva, as atividades 
devem ser selecionadas e planejadas com base na aprendizagem das crianças e não no desempenho que elas têm (PCE/EI, 2015, p. 18).

A partir desta concepção curricular, a Educação Infantil da Escola de Educação Básica da Universidade Federal de Uberlândia, Eseba, optou por trabalhar com a pedagogia de projetos de forma que contemple o currículo e ao mesmo tempo priorize as demandas infantis com toda sua carga de investigação e curiosidade cotidiana própria das crianças. Como esclarece Barbosa; Harn (2008),

Os projetos abrem para a possibilidade de aprender os diferentes conhecimentos construídos na história da humanidade de modo relacional e não-linear, propiciando às crianças aprender através de múltiplas linguagens, ao mesmo tempo em que lhes proporcionam a reconstrução do que já foi aprendido (BARBOSA; HARN, 2008, p. 35).

Os projetos pedagógicos para a Educação Infantil também são uma forma de trabalho proposta pelo Referencial Curricular do Ministério da Educação, no qual afirmam que:

Os projetos são conjuntos de atividades que trabalham com conhecimentos específicos construídos a partir de um dos eixos de trabalho que se organizam ao redor de um problema para resolver ou um produto final que se quer obter. Possui uma duração que pode variar conforme o objetivo, o desenrolar das várias etapas, o desejo e o interesse das crianças pelo assunto tratado. Comportam uma grande dose de imprevisibilidade, podendo ser alterado sempre que necessário, tendo inclusive modificações no produto final. Por partirem sempre de questões que necessitam ser respondidas, possibilitam um contato com as práticas sociais reais. Dependem, em grande parte, dos interesses das crianças, precisam ser investigativos, representar uma questão comum para todas e partir de uma indagação da realidade. É importante que os desafios apresentados sejam possíveis de serem enfrentados pelo grupo de crianças. Um dos ganhos de se trabalhar com projetos é possibilitar às crianças que a partir de um assunto relacionado com um dos eixos de trabalho, possam estabelecer múltiplas relações ampliando suas ideias sobre um assunto específico, buscando complementações com conhecimentos pertinentes aos diferentes eixos. Esse aprendizado serve de referência para outras situações, permitindo generalizações de ordens diversas (BRASIL, 1998, p. 57).

Desta maneira, relatamos a seguir o trabalho desenvolvido na educação infantil, tendo por base a pedagogia de projetos e a exploração das diversas linguagens, e considerando, assim como esclarece Barbosa e Horn (2008) que os 
pesquisar, a procurar informações, a exercer a crítica, a duvidar, a argumentar, a opinar, a pensar, a gerir as aprendizagens e a refletir coletivamente.

\section{Desenvolvimento}

Todo início de ano, procuramos conhecer as crianças de modo que a partir do olhar, da escuta, da demanda e da curiosidade infantil possamos juntos elaborar uma proposta de trabalho. Desta maneira, após um período de adaptação e entrosamento, é possível vislumbrar algumas temáticas e/ou problemáticas para o desenvolvimento de um projeto com a turma de alunos.

Ao longo de vários anos de trabalho com as crianças na educação infantil na Eseba, muitos projetos já foram desenvolvidos a partir da proposta da escuta e envolvimento com as crianças. As temáticas variaram muito, por partirem do grupo. Alguns temas que já foram trabalhados: golfinho, meteoro, natureza, cigarra, macaco, cachorro, macarrão, dinossauro e foguete.

O gatilho inicial pode ser feito a partir de uma votação da turma sobre uma temática que gostariam de pesquisar ou sobre um problema que surgiu na turma e a partir dele, é construído um projeto de pesquisa. Por isso, a elaboração do projeto é a partir de um tema e/ou problema definido pelas crianças e mediado pela professora da turma, o que torna diferente a cada ano letivo.

Uma mesma turma pode desenvolver mais de um projeto no ano, se caso essa for a demanda. O tema pode ser fomentado por algo que foi encontrado e gerou curiosidade, como por exemplo ovinhos de algum animal, uma pena, casca de cigarra, um alimento que gostem muito, uma brincadeira que se repete no cotidiano, enfim, a variedade é imensa e a escuta do professor precisa estar aberta e aguçada para perceber as nuances de cada assunto surgido e aos poucos o projeto tomar corpo. Assim é possível provocar aprendizagens, fazer conexões e relações entre informações, ideias, sentimentos e ações.

Após a definição do tema seguimos alguns passos que contribuem na organização da estruturação do projeto, bem como garantir a fidedignidade aos conhecimentos prévios das crianças, às suas hipóteses e deduções. São estes: identificar com as crianças o que já sabem sobre o tema escolhido; levantar o que eles gostariam de saber (suas dúvidas, problemas, hipóteses); estabelecer como 
será possível encontrar as respostas às perguntas levantadas (qual metodologia a ser utilizada) e finalmente, ao final do projeto, relatar o que conseguiram aprender (avaliação).

A escola, diante desta vivência, tornou-se cada vez mais, mediadora entre o conhecimento das crianças e o conhecimento socialmente construído pela sociedade. Portanto o papel da escola neste processo foi essencial para promover a relação dialética entre o saber do aluno e os novos conhecimentos, assim como diz Rego (2010):

A escola desempenhará bem seu papel, na medida em que, partindo daquilo que a criança já sabe (o conhecimento que ela traz de seu cotidiano, suas ideias a respeito dos objetos, fatos e fenômenos, suas "teorias" acerca do que observa no mundo), ela for capaz de ampliar e desafiar a construção de novos conhecimentos, na linguagem vygotskiana, incidir na zona de desenvolvimento potencial dos educandos. Dessa forma poderá estimular processos internos que acabarão por se efetivar, passando a constituir a base que possibilitará novas aprendizagens (REGO, 2010, p. 108).

A seguir constam alguns quadros, que ilustram o registro das etapas relatadas. Cada etapa é elaborada com a turma e registrada de forma que componha o portfolio do projeto, podendo observar o caminho percorrido pela turma, desde a escolha do tema, as etapas perpassadas, as atividades realizadas, registros com fotos de momentos vivenciados, atividades de campo, enfim, todo o processo vivenciado durante o projeto. Desta forma não terá apenas um produto final, e sim, uma história para contar de todo este trabalho desenvolvido juntamente com as crianças, e não para as crianças.

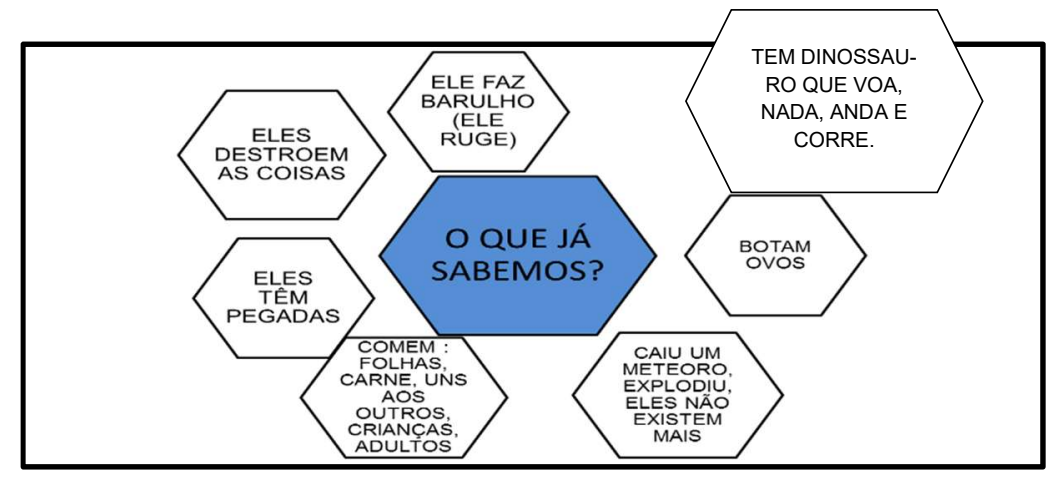

QUADRO 1: levantamento do que já sabem sobre o tema.(Projeto Dinossauro) 
Muitas vezes a partir deste primeiro levantamento é possível vislumbrar algumas hipóteses e problemática a serem levantadas, mas que não são percebidas conscientemente pelas crianças e a professora terá que realizar o papel mediador deste processo de criação de questionamentos, provocando as crianças a pensarem sobre o que disseram. Nesse momento, surgem conflitos entre as crenças de cada um e então a discussão em torno da problemática torna o processo ainda mais enriquecedor, pois elas precisam argumentar ou refletir sobre suas hipóteses. A partir de então, criam-se as perguntas sobre o tema. Um exemplo do conflito de crenças aconteceu durante o projeto Dinossauro, o qual alguns alunos diziam que o dinossauro não existia mais e outros diziam que sim, porque viram no filme. Diante desta incerteza entre as crianças, foram lançadas duas perguntas que constam no quadro abaixo: o dinossauro ainda existe?O dinossauro do filme é de verdade?

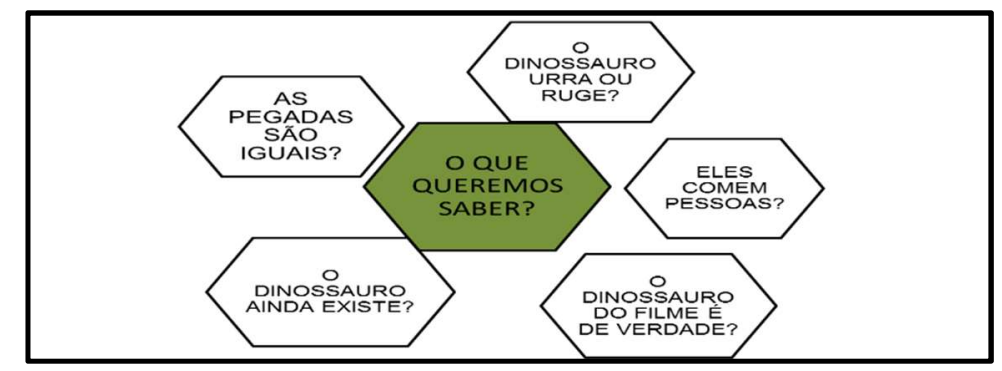

QUADRO 2: levantamento do que querem saber sobre o tema.(Projeto Dinossauro)

Em seguida, partimos para pensar na metodologia. Neste momento as crianças são questionadas sobre o que consideram que precisam fazer para descobrir as respostas às perguntas feitas. Durante os últimos anos de trabalho na educação infantil, as crianças têm mostrado que estão ficando cada vez mais limitadas ou acomodadas por acreditarem que só podem pesquisar pela via da internet, isto é, supõem que pesquisa apenas acontece no computador, no tablete, no celular, no whatsapp, no google e assim por diante. No entanto, não avançam sozinhas para imaginar outros caminhos metodológicos. Mais uma vez a mediação da professora se faz necessário, de forma a instigá-las a buscar outras maneiras de pesquisar, como por exemplo, indo à biblioteca da escola, procurando em livros que tenham em casa, realizando uma entrevista com pessoas que estudaram sobre 0 
assunto, fazendo uma visita de campo, coletando dados com fotos e filmagens, enfim, ampliando o repertório metodológico de busca e acesso às informações.

A partir deste início de estruturação do projeto, a professora organiza sistematicamente o trabalho de maneira a compor no currículo para a educação infantil, identificando as noções, conceitos, competências e estratégias de cada área curricular, imersa na temática do projeto. Assim, por exemplo, no Projeto Macarrão, foi estruturado a partir das demandas das crianças distribuídas nos quadros (o que sabemos, o que queremos saber e como saberemos) um novo quadro para linguagem da matemática, oral e escrita, movimento, desenvolvimento afetivo e emocional, natureza e sociedade. Embora as ações sejam feitas muitas vezes de maneira interdisciplinar, a construção do quadro contribui o olhar para que todas as linguagens sejam contempladas.

\begin{tabular}{|c|c|c|}
\hline Noções e conceitos & Competências & Estratégias \\
\hline $\begin{array}{l}\text { - } \quad \text { Origem do macarrão } \\
\text { - Como faz a massa do } \\
\text { macarrão. } \\
\text { - Alimentos naturais e } \\
\text { alimentos } \\
\text { industrializados. }\end{array}$ & $\begin{array}{l}\text { - Conhecer o lugar de origem do } \\
\text { macarrão, como foi inventado } \\
\text { e a cultura do local. } \\
\text { Conhecer como faz a massa do } \\
\text { macarrão, quais os } \\
\text { ingredientes. } \\
\text { - Perceber a diferença entre } \\
\text { estes tipos de alimentos, os } \\
\text { que são naturais e os que são } \\
\text { fabricados. }\end{array}$ & 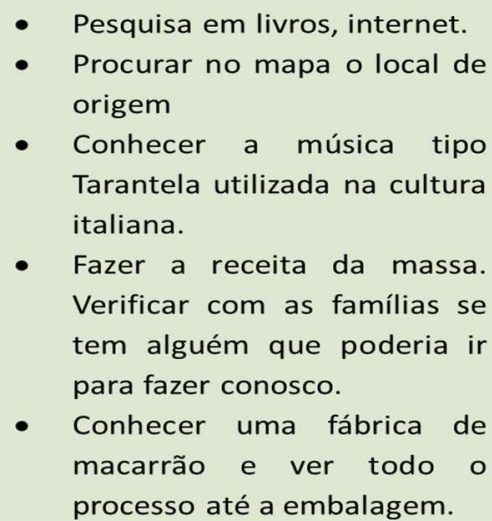 \\
\hline
\end{tabular}

QUADRO 3: Quadro do projeto Macarrão na área curricular Natureza e Sociedade

\begin{tabular}{|c|c|c|}
\hline Noções e conceitos & Competências & Estratégias \\
\hline $\begin{array}{l}\text { - Identificação, descrição } \\
\text { e classificação. } \\
\text { - Medidas } \\
\text { - Simetria e sequência. } \\
\text { - Contagem }\end{array}$ & $\begin{array}{l}\text { - Observar as características dos } \\
\text { tipos de macarrão e realizar uma } \\
\text { classificação. Pensar em critérios } \\
\text { como: tamanho, formato, } \\
\text { função... } \\
\text { Compreender a noção de } \\
\text { medidas de volume e peso } \\
\text { Organizar uma mandala com } \\
\text { diferentes tipos de macarrão de } \\
\text { forma que tenha uma estética } \\
\text { simétrica sequenciada. } \\
\text { Reconhecer a quantidade de } \\
\text { votos para o nome do mascote. }\end{array}$ & $\begin{array}{l}\text { - Pedir às famílias tipos } \\
\text { diferentes de macarrão para } \\
\text { organizarmos uma coleção. } \\
\text { Classificar os tipos de } \\
\text { macarrão. } \\
\text { - Culinária: produção da massa } \\
\text { - Construção de uma mandala } \\
\text { utilizando a base de um prato } \\
\text { descartável e diferentes tipos } \\
\text { de macarrão. } \\
\text { Registrara quantidade de votos } \\
\text { ao mascote e relacionar com } \\
\text { objetos. }\end{array}$ \\
\hline
\end{tabular}

QUADRO 4: Quadro do projeto Macarrão na área curricular Matemática. 
Estes quadros que compõem o currículo são construídos ao longo do processo de efetivação do projeto, pois eles podem ser modificados, na medida em que as situações são vivenciadas e surgem novas demandas. O trabalho com projeto não caminha de forma linear, não é um caminho reto. Ele se reconfigura a todo o momento, pois embora tenhamos em mente as perguntas iniciais do projeto, podem surgir outras visto que um de nossos objetivos era suscitar nas crianças este caráter investigativo e insaciável de conhecimento.

Durante os projetos, utilizamos diversos recursos tanto para pesquisa quanto para registro do vivido e aprendido. Sendo assim, o uso de fotos, filmagens, pesquisa de campo, leituras de diversos portadores de textos (gibis, enciclopédias, revistas, panfletos...) histórias, vídeos, documentários, entrevistas, imagens, brincadeiras, jogos, tecidos, arte, músicas, desenhos, anotações, cartas, construção de livretos, construções tridimensionais com sucatas, cartazes, atividades são alguns exemplos do que utilizamos neste período.

O processo avaliativo, sempre foi feito juntamente com as crianças, e também pode conter diversas formas de avaliação, dependendo do projeto e da turma. Algumas possibilidades são: reler as perguntas feitas no início do projeto e das outras que surgiram e verificar se conseguem responder; construir um portfolio contendo todo o processo e a medida que for revendo as produções rememorar o vivido; realizar uma mostra à comunidade escolar na qual relate e expõe os aprendizados; selecionar fotos que marcam momentos importantes do projeto e pedir às crianças que comentem o que lembram, o que consideram mais relevante... Enfim, o processo avaliativo do projeto se assemelha muito com o que já é vivenciado na educação infantil, o qual ressalta o progresso individual e coletivo, ao longo do processo escolar, observando e registrando o envolvimento de cada criança, seu comprometimento, sua capacidade de iniciativa, criação e participação.

\section{Considerações finais}

Os projetos pedagógicos são elaborados e executados para que as crianças aprendam a estudar, a pesquisar, a procurar informações, a exercer a crítica, a duvidar, a argumentar, a opinar, a pensar, a gerir as aprendizagem, a refletir coletivamente e, o mais importante, são elaborados e executados com as crianças e 
não para as crianças (BARBOSA; HORN, 2008). Por este motivo o planejamento é feito concomitantemente com as ações e as atividades vão sendo construídas "durante o caminho".

O que precisa estar claro ao se trabalhar com projetos na educação infantil são os objetivos do trabalho, quais os princípios que consideram importantes e relevantes e que norteiam a proposta pedagógica da escola. Desta maneira, é possível caminhar pelo tema escolhido pelas crianças de forma instigante, apoiando as sugestões e anseios dos alunos sem perder os objetivos do trabalho ao longo do processo vivido.

O mais evidente nos projetos, é perceber o envolvimento e o entusiasmo dos alunos com o tema e da maneira como a aprendizagem acontece de maneira natural e significativa. Durante os projetos é nítida a participação efetiva das crianças, propondo estratégias, disseminando o assunto em suas casas, contagiando os outros colegas e principalmente, curiosos em descobrir o mundo. As crianças são sujeitos ativos no processo de construção do conhecimento.

\section{Referências}

BARBOSA, Maria Carmem Silveira; HORN, Maria da Graça Souza. Projetos

Pedagógicos na Educação Infantil. Porto Alegre: Artmed, 2008.

BRASIL. Ministério da Educação e do Desporto. Secretaria de Educação

Fundamental. Referencial Curricular Nacional para Educação Infantil. Brasília:

MEC/SEF, 1998. Volume I.

ESCOLA DE EDUCAÇÃO BÁSICA DA UNIVERSIDADE FEDERAL DE UBERLÂNDIA. Parâmetros Curriculares da Educação Infantil- PCE/EI. Uberlândia, MG, 2015.

OLIVEIRA, P. F.; FERREIRA, J. M. Apresentando uma proposta curricular para educação infantil. In: SILVA, F. D.; SOUZA, V. A. (Orgs.) Educação Infantil: docência, gestão, saberes e práticas educacionais. Uberlândia: UFU, PROEX, 2016. p. 53-64.

OSTETO, Luciana E. (org.) Encontros e encantamentos na educação infantil: partilhando experiências de estágios. Campinas: Papirus, 2000. 
REGO, Teresa Cristina. Vygotsky: uma perspectiva histórico-cultural da educação.Petrópolis, RJ: Vozes, 2010. 


\section{GT 09}

\section{Educação Estética, Cultural e Política}

